удК 334.75

Л. А. Казарина

Байкальский государственный университет, 2. Иркутск, Российская Федеращия

\title{
АУТСОРСИНГ ФУНКЦИЙ КАК ИНСТРУМЕНТ ПОВЫШЕНИЯ КОНКУРЕНТОСПОСОБНОСТИ ФИРМЫ
}

\begin{abstract}
АНнотАЦИя. Аутсорсинг является эффективным инструментом повышения конкурентоспособности фирмы, позволяющим ее менеджменту сконцентрировать ресурсы на ключевых функциях. Необходимость усиления сервисной составляющей производства требует от компаний совмещения требований эффективности производства с учетом предпочтений клиентов. Необходимость повышения качества обслуживания приводит появлению на предприятии второстепенных функций, деятельность компании становится более разнообразной, а управление фирмой более сложным. Это требует новых ресурсов и широкой квалификации персонала, что повышает издержки и потенциально снижает конкурентоспособность. Аутсорсинг позволяет сосредотачивать ресурсы на избранных процессах. Функции, не относящиеся к базовой деятельности и связанные с непрофильными активами, передаются специализированным организациям. В статье выделяются основные причины использования компаниями аутсорсинга - необходимость снижения издержек и повышение качества обслуживания. Выявлены вторичные преимущества аутсорсинга, показаны функции, которые преимущественно передаются специализированным организациям. Определены основные риски аутсорсинга функций и показаны пути их снижения.
\end{abstract}

кЛЮЧЕВЫЕ словА. Аутсорсинг; конкурентоспособность; непрофильные активы; производство.

ИНФОРМАЦИЯ О СТАТЬЕ. Дата поступления 09 января 2018 г.; дата принятия к печати 19 марта 2018 г.; дата онлайн-размещения 09 апреля 2018 г.

L. A. Kazarina Baikal State University, Irkutsk, Russian Federation

\section{OUTSOURCING OF FUNCTIONS AS A TOOL OF INCREASING COMPANY'S COMPETITIVENESS}

\begin{abstract}
Outsourcing is an effective tool of increasing the competitiveness of a company allowing its management to concentrate the resources on the key functions. The necessity of strengthening the service component of production makes the companies combine the requirements of the production efficiency, taking into account the preferences of customers. The necessity of improving the quality of service leads to the emergence of secondary functions in the enterprise, the company's activities become more diverse, and the management of the company becomes more complicated. This requires new resources and a broad qualification of personnel, which increases the expenses and potentially reduces the competitiveness. Outsourcing allows to focus the resources on the selected processes. The functions that are not related to the basic activities and are associated with the non-core assets are transferred to the specialized organizations. The article highlights the main reasons of using the outsourcing for companies, which makes it necessary to reduce the expenses and improve the quality of service. It reveals the secondary advantages of the outsourcing and presents the functions that are primarily transferred to the specialized institutions. The main risks of the outsourcing of functions are identified and the ways of their decrease are presented.

KEYWORDS. Outsourcing; competitiveness; non-core assets; communication; production. ARTICLE INFO. Received January 09, 2018; accepted March 19, 2018; available online April 09, 2018.
\end{abstract}

(C) Л. А. Казарина, 2018

\section{Baikal Research Journal}


Одой из основных целей управления фирмой является обеспечение ее конкурентоспособности в настоящем и будущем. Конкурентные преимущества становятся ключевыми факторами, обеспечивающими предприятию более выгодное положение по сравнению с конкурентами, а также достижение стратегических и тактических целей [1]. В современной экономике конкурентоспособность фирмы во многом зависит от ее способности предоставлять потребителям качественное обслуживание в процессе предоставления им своей продукции. Товар сегодня предлагается потребителю товар не только как материальный объект, но и как комплекс, включающий разнообразные услуги. Все больше конкурентоспособность фирмы обеспечивает совокупное предложение «товара-услуги». Поэтому важным инструментом усиления конкурентных позиций предприятия на рынках товаров и услуг становится комплексное обслуживание потребителей в процессе реализации их заказов.

Существенные изменения предпочтений потребителей, необходимость постоянного учета этих изменений приводят к тому, что эволюционирует само понятие «товар», а деятельность предприятий становится все более разнообразной и многоплановой, увеличивается ее сервисная составляющая. Расширяющееся множество целей, задач и функций требует от фирм все более разнообразных ресурсов и широкой квалификации персонала. Подобная диверсификация деятельности в значительной степени усложняет процесс управления и организационную структуру, потенциально снижая конкурентоспособность фирмы на рынке и ставя ее руководство перед необходимостью корректировки стратегических и тактических ориентиров.

Фирмы, осуществляющие многофункциональную, многоэтапную или диверсифицированную деятельность, стали пересматривать собственные приоритеты и сосредотачивать ресурсы на ограниченном объеме избранных (ключевых, базовых) процессов и активностей. Функции, не относящиеся к базовой деятельности, постепенно (частично или полностью) передаются другим фирмам, специализирующимся на них. Такая тенденция к аутсорсингу (от англ. outsorcing) отражает особенности современного этапа общественного разделения труда, характеризующегося углублением интеграционных процессов.

Термин аутсорсинг означает «использование внешних источников» (out внешний, source - источник). В современном бизнесе под аутсорсингом понимается способ совершенствования деятельности предприятий путем передачи определенных функций сторонним организациям, специализирующимся на их выполнении, имеющим соответствующее оборудование и квалифицированный персонал. Передача ряда ранее органически присущих компании функций внешним исполнителям стала одним из ключевых факторов роста конкурентоспособности организации во многих отраслях экономики. Заключение договоров об аутсорсинге ряда функций позволяет компаниям сохранять имеющиеся конкурентные преимущества и приобретать новые благодаря рациональному использованию имеющихся ресурсов.

К основным причинам, побуждающим фирмы к аутсорсингу ряда функций, относятся:

- необходимость снижения затрат, изменения структуры издержек;

- потребность в повышении качества услуг для конечного потребителя. Передаваемая функция является для фирмы-поставщика основной деятельностью, поэтому она направляет на ее совершенствование значительные ресурсы в целях собственной конкурентоспособности на рынке данной деятельности;

- дефицит или отсутствие необходимого опыта и оборудования, позволяющего осуществлять необходимые функции на достаточно высоком уровне;

\section{Baikal Research Journal}


- желание фирмы приобрести компетенции в новых видах деятельности, интересных для ее потребителей;

- стремление менеджмента к повышению эффективности функционирования всей организационной системы. Современная экономика требует высокой компетенции менеджеров в различных областях деятельности. Если одна или более областей управляются неверно, это негативным образом сказывается на эффективности всей организации. Экстернализация отдельных функций третьей стороне часто является методом решения этой проблемы.

В результате передачи части функций снижается собственная доля участия фирмы в создании стоимости. Данный показатель отражает соотношение работ, произведенными собственными силами фирмы, к общим произведенным работам по созданию стоимости поставляемого товара или услуги.

Аутсорсинг функций не следует считать разновидностью традиционных субподрядных отношений. Субподряд предполагает, как правило, разовые взаимодействия со сторонней организацией для выполнения отдельных, часто не связанных между собой по содержанию и разорванных во времени работ в локальных областях деятельности. Аутсорсинг же это не традиционные отношения между организациями, строящиеся по схеме «сделка за сделкой», а управленческая стратегия, нацеленная на долгосрочные партнерские связи по профессиональной поддержке бесперебойной работоспособности бизнес-процессов [2].

Реализация аутсорсинга позволяет компании двигаться к наиболее эффективному, «бережливому» производству, в котором исключены ненужные действия, а оставшиеся выстраиваются в наиболее рациональную непрерывную последовательность. Концепция бережливого производства предполагает, что «большинство компаний сегодня делают слишком много и много из этого делают плохо. В мире бережливой экономики каждая компания будет браться за более узкий круг задач, но выполнять их хорошо» [3, с. 223].

Аутсорсинг можно разделить на два основных вида, граница между которыми достаточно условна, - производственный аутсорсинг и аутсорсинг бизнес-процессов. Производственный аутсорсинг предполагает передачу специализированным организациям отдельных или всех производственных функций. Такая экстернализация производства позволяет повысить качество продукции, сделать производство более гибким, уменьшить потребность в капитальных вложениях, сосредоточиться на разработке новых перспективных продуктов, снизить издержки за счет использования более дешевой рабочей силы. Такой процесс имеет давнее и широкое распространение в экономике многих стран, характерным примером является передача европейскими компаниями производственных операций предприятиям азиатских стран.

Второй вид аутсорсинга - аутсорсинг бизнес-процессов - предполагает передачу сторонним специализированным организациям функций, не относящихся к бизнес-образующим, но необходимых для поддержания и развития основной деятельности.

Рост использования аутсорсинга непроизводственных функций начался со сферы информационных технологий в 1970-х гг. Причиной этого стала высокая стоимость процессов обработки данных. Крупные компании стали прибегать к услугам вычислительных центров для решения задач, связанных с применением компьютеров. Определяющим фактором решения о передаче таких функций стало осознание менеджментом компаний того факта, что пригодится тратить огромные средства на приобретение аппаратного обеспечения, которое не могло долго поддерживать конкурентоспособность. В аппаратуру и программное обеспечение необходимо было инвестировать все больше средств, а подразделения по ИТ, не

\section{Baikal Research Journal}

электронный научный журнал Байкальского государственного университета 
являясь частью основной деятельности, отнимают существенные финансовые и временные ресурсы компаний. При переводе этих подразделений сторонним фирмам затраты снижались на 20-40\% [4].

Постепенно в сферу аутсорсинга стали включаться и другие непроизводственные функции: финансовый и бухгалтерский учет, управление персоналом, логистика, маркетинг. Тенденция к аутсорсингу стала усиливаться с глобализацией торговли и развитием Интернета. Сейчас компании могут передавать для исполнения другим организациям практически любую из своих функций, если это позволяет сохранить или даже повысить конкурентоспособность фирмы-аутсорсера. Производственные компании передают на аутсорсинг, главным образом, функции, связанные с непрофильными активами - ремонтное обслуживание, вспомогательное производство, охрану, транспортные и погрузочно-разгрузочные работы, маркетинг, сбыт, энергетическое обслуживание и т.п. [5]

В современной российской экономике характерным примером передачи части ранее исполняемых самостоятельно бизнес-процессов за пределы компании является аутсорсинг логистических функций, который заключается в отказе от использования собственных ресурсов фирмы для исполнения необходимых логистических операций и передаче этих функций сторонней организации. Наряду с другими стратегиями логистического управления (минимизации общих логистических издержек, повышения качества логистического сервиса и другими) стратегия логистического аутсорсинга становится все более востребованной в деятельности бизнес-организаций. Стремление многих предприятий снизить накладные расходы и повысить качество логистических активностей посредством их передачи более опытным в этой области профессионалам вызвало появление на товарных рынках специализированных логистических фирм. Такие фирмы могут исполнять практически любые работы в рамках всех элементов логистический системы предприятия: склады, запасы, средства транспортировки, средства связи и др. [6]

Наряду с термином «логистический аутсорсинг» (logistics outsourcing) в зарубежной литературе более часто используются термины contract logistics (контрактная логистика) и «third-party logistics (TPL)» или «3rd party logistics (3PL)». Эти термины отражают участие в логистической деятельности так называемых «трех сторон»: поставщиков готовой продукции или материальных ресурсов, их клиентов и логистических операторов. Развитие нового поколения логистических фирм и активное включение в контрактную логистику компаний, занимающихся управленческим консалтингом, приводит к расширению числа участников отношений аутсорсинга до четырех - производителя, консалтинговой компании, логистического провайдера и потребителя. В этих случаях зарубежные авторы начинают использовать термин «Fourth Party Logistics» (сокращенно - 4PL) [7].

Среди множества непроизводственных функций на российских предприятиях объектом аутсорсинга наиболее часто становятся транспортные активности [8]. Большие объемы перевозок ресурсов и готовой продукции, существенная доля транспортных издержек в себестоимости продукции, высокие требования клиентов к своевременности доставки грузов требуют тщательного взвешивания и сопоставления вариантов осуществления этих активностей. Многие производственные и непроизводственные компании стоят перед выбором между содержанием и эксплуатацией собственной транспортной базы и покупкой услуг специализированных транспортных организаций. Перевод перевозок на аутсорсинг часто позволяет повысить конкурентоспособность производителей, избежать неэффективность использования подвижного состава, снизить транспортные издержки [9].

Все более распространенным типом аутсорсинга является аутстаффинг, предполагающий вывод сотрудников за штат компании-заказчика и перевод в компа-

\section{Baikal Research Journal}

электронный научный журнал Байкальского государственного университета 
нию-провайдера. При этом сотрудник продолжает выполнять свои прежние обязанности, но его работодателем является уже компания-провайдер. Аутстаффинг используется когда у предприятия есть подразделения, которые не могут быть полностью загружены работой; когда установлены ограничения на численность персонала компании, когда необходимо сократить затраты, связанные с социальными взносами, работой по ведению кадрового делепроизводства, начислением заработной платы и т.п. [10]

Существует два основных варианта передачи функций и операций специализированным исполнителям: аутсорсинг как компенсация нестабильности объемов заказов и аутсорсинг как форма специализации предприятий. Первый вариант целесообразно использовать, когда мощности фирмы или ее пропускной способности не хватает для выполнения заказов потребителей в полном объеме, а создание новых мощностей невозможно по техническим или экономическим причинам. Специализированная организация может выполнять те же функции и операции, что и фирма-аутсорсер, но только в тех объемах, которые превышают мощности последней. Такой вариант может использоваться на временной основе, например, в периоды сезонного роста спроса. Второй вариант аутсорсинга предполагает разделение осуществляемых процессов на основе специализации. То есть часть необходимых функций фирма выполняет самостоятельно, а остальные, особенно требующие особых технологий и оборудования, приобретаются в виде услуг сторонних организаций. Эти организации обладают специальными навыками мощностями, необходимыми для выполнения определенных логистических процессов. Такой вариант имеет более широкие временные горизонты.

Аутсорсинг, включающий широкий ряд выполняемых функций компании, предполагает определенную, а нередко и существенную, реструктуризацию как внешних отношений компании-аутсорсера, так и ее внутренних процессов, меняется состав выполняемых работ, профессионально-квалификационная структура персонала, состав подразделений и их взаимосвязи. Сегодня в промышленно развитых странах большинство предприятий в той или иной степени прибегает к услугам специализированных фирм, а оплата этих услуг составляет значительную часть общих издержек фирм-аутсорсеров.

Использование аутсорсинга позволяет быстро реагировать на изменения динамичного рынка, не отставая от конкурентов или даже опережая их. Передача части функций субподрядчику дает возможность сконцентрировать собственные ресурсы на основных, стратегически важных направлениях бизнеса. Привлечение специализированных фирм обеспечивает снижение себестоимости передаваемых поставщику функций за счет его специализации.

Помимо сокращения затрат, улучшения из структуры и повышения качества обслуживания потребителей фирма-аутсорсер в результате грамотной передачи функций специализированным фирмам получает ряд дополнительных выгод.

1. Менеджмент фирмы не отвлекается на второстепенные функции и получает возможность сосредоточиться на активностях, обеспечивающих компании стратегический успех.

2. Конкурентные позиции фирмы усиливаются за счет коалиций с лучшими поставщиками услуг - рекламными агентствами, конструкторами и дизайнерами, каналами распределения, финансовыми компаниями и т.п. Всякий раз, когда компания производит самостоятельно услугу, которую другие покупают или производят более эффективно вовне, она жертвует своим конкурентным преимуществом.

3. Внутренние издержки фирмы снижаются за счет ликвидации излишнего бюрократизма, снижения политического давления, направленного на увеличением бюджетов отдельных подразделений.

\section{Baikal Research Journal}

электронный научный журнал Байкальского государственного университета 
4. Менеджменту компаний предоставляется возможность более тщательно анализировать, какие подразделения важны для успеха, а какие операции (функции) могут быть сокращены до минимального уровня, что можно приобретать «как товар», а что следует сохранить как источник конкурентных преимуществ.

5. Компания становится более компактной, уменьшается количество иерархических уровней. В результате фирма становится более мобильной, сокращается длина цепочки принятия решений, компания более быстро реагирует на изменения на рынке.

6. Усиливается фокусирование на найме, развитии и мотивации сотрудников, которые создают наибольшую ценность в тех областях, где компания имеет ключевые компетенции.

7. Менеджмент движется от функциональных умений и способности управлять бюрократическими процессами в направлении способности управлять контрактными отношениями.

8. Происходит полная или частичная передача рисков. Каждый процесс в организации сопровождается определенными рисками, которые сопровождают его функционирование. При аутсорсинге риски переходят к организации, исполняющей услуги.

9. Облегчается выход компании на новые рынки. Фирма, исполнитель переданных работ, может исполнять и представительские функции, играя своего рода агентскую роль [11].

Таким образом, аутсорсинг позволяет компаниям решить многие проблемы конкурентоспособности на рынке путем сокращения издержек, повышения качества продукции и услуг, ускорения адаптации к изменяющимся условиям, снижения возможных рисков, повышения эффективности использования человеческого капитала, совершенствования организационной структуры и т.п.

Однако аутсорсинг нельзя считать универсальным средством решения всех или большинства проблем конкурентоспособности. Передача функций третьей стороне может создавать дополнительные риски и проблемы для компании-аутсорсера.

1. Сотрудники компании-поставщика могут не проявлять таких же умений и лояльности как сотрудники компании-клиента. Работники компании-аутсорсера имеют многолетний опыт выполнения соответствующих функции, профессионального общения с коллегами, непосредственных контактов с собственными клиентами. Потеря такого контакта, происходящего в результате передачи функций третьей стороне и перевода к ней сотрудников, может негативно влиять на качество обслуживания клиентов. Одним из решений этой проблемы является размещение офиса или помещения по предоставлению услуг как можно ближе к действующим помещениям компании-аутсорсера [4]. Такое размещение позволит получить преимущества от тесного общения переведенных сотрудников с работниками других подразделений компании-аутсорсера. Отдаленное же размещение будет приводить к тому, что сотрудники будут терять знания и навыки, связанные с основной деятельностью.

2. Компания-клиент теряет навыки выполнения передаваемых функций. Однако если руководители, оставшиеся в компании и пользующиеся услугами бывших подчиненных, будут по-прежнему полностью осведомлены о происходящем в переданных функциях, потери навыков не будет происходить.

3. Снижение мотивации оставшихся в компании сотрудников, особенно руководителей среднего и нижнего уровней, из-за возникающих у них сомнений в возможностях карьерного роста. Этот риск снижается, если после передачи функций у этих сотрудников появляется перспектива участвовать в расширении деятельности фирмы, а также возможности для обучения и повышения квалификации [12].

\section{Baikal Research Journal}


4. Изменение законодательства и особенностей рынка. Например, в результате аутсорсинга большая часть продукции компании «Nike» производилась на заводах в Азии. Постепенно эти заводы стали производить удовлетворяющие требованиям товары при низких производственных затратах. Однако компания стала испытывать давление общественности из-за якобы чрезмерной эксплуатации рабочей силы. В результате компания расторгла договоры с некоторыми заводами по причине более низких ставок оплаты и худших условий труда, чем было предусмотрено соглашением. Возникновению таких специфических рисков может воспрепятствовать включение в условия контракта возможности регулярного доступа сотрудников компании-аутсорсера на предприятия поставщика.

5. Рост зависимости компании от поставщика, доминирование поставщика в контрактных отношениях. Данный риск может быть снижен в включением в контракт положения о возможности выхода аутсорсера из соглашения и заключения альтернативного соглашения. Особенно это важно когда в результате перевода мощностей и помещений к поставщику у него появляется возможность обслуживать на них и других клиентов.

6. Невозможность удовлетворения компанией-клиентом изменяющихся требований собственных потребителей. Обычно уровень и обслуживания потребителей фиксируются в контракте. Однако следует предусмотреть и возможность разрешения аутсорсеру непредвиденных требований, в том числе связанных с различными нововведениями, которые невозможно было предусмотреть в момент заключения контракта.

7. Сбои в обслуживании при передаче функций. Период подготовки контракта обе стороны должны тщательно оценить риски срывов в выполняемых процессах. Следует разработать подробный план передачи функций, учитывающий возможные потребности компаний, заключать соглашения о взаимной поддержке в переходный период.

8. Риски утери важной коммерческой информации [13]. Такие риски относятся к одной главных причин, по которым в России передаются на аутсорсинг, главным образом, второстепенные функции [8]. Сохранение коммерческой тайны - важное условие, которое следует учесть при составлении контракта.

Аутсорсинг функций позволяет компании усилить конкурентные преимущества. Однако его использование требует высокой квалификации менеджмента и знания обоснованных методов его осуществления. Особого внимания требует процесс подготовки и заключения контрактов на передачу функций [14]. Аутсорсинг является стратегическим решением, поэтому и совершаемые при экстернализации функций ошибки чаще всего имеют стратегический масштаб. Их устранение потребует существенных расходов и значительных затрат времени.

\section{Список использованной литературы}

1. Бекетов Н. В. Проблемы управления экономической устойчивостью и конкурентоспособностью предприятий / Н. В. Бекетов // Национальные интересы: приоритеты и безопасность. - 2008. - № 4 (25). - С. 23-27.

2. Давыдкин Е. В. Аутсорсинг как функция эффективного управления бизнес процессами / Е. В.Давыдкин // Актуальные вопросы экономических наук. - 2011. - № 22-2. C. $139-144$.

3. Вумек Джеймс П. От бережливого производства к бережливому предприятию / Джеймс П. Вумек, Дэниел Т. Джонс // Построение цепочки создания стоимости. - М. : Юнайтед Пресс, 2007. - С. 221-251.

4. Хейвуд Дж. Б. Аутсорсинг: в поисках конкурентных преимуществ / Дж. Б. Хейвуд. - М. : Вильямс, 2002. - 176 с.

\section{Baikal Research Journal}


5. Диких Ю. В. Аутсорсинг в процессе создания готовой продукции / Ю. В. Диких // Актуальные проблемы гуманитарных и естественных наук. - 2013. - № 12-1. - С. 264-267.

6. Колодин В. С. Логистические системы в производственно-коммерческой деятельности / В. С. Колодин // Известия Иркутской государственной экономической академии. 2011. - № 6. - С. 99-103.

7. Казарина Л. А. Логистические услуги / Л. А. Казарина. - Иркутск : Изд-во БГУЭП, 2006. $-158 \mathrm{c}$.

8. Кузнецова А. С. Аутсорсинг как инструмент выживания в современной экономике / А. С. Кузнецова // Актуальные вопросы экономических наук. - 2011. — № 18. - С. 60-65.

9. Аутсорсинг бизнес процессов как важный фактор рациональной организации транспортного обслуживания (на материалах мебельных предприятий региональной экономики) / В. М. Бугаков [и др.] // Регион: системы, экономика, управление. — 2014. - № 1 (24). C. $79-86$.

10. Калашников А. Н. Аутсорсинг как форма эффективного использования человеческого капитала / А. Н. Калашников // Белгородский экономический вестник. - 2011. № 1-2 (61-62). - С. 42-46.

11. Ившин С. Ю. Комплексный анализ дефиниции «логистический аутсорсинг» / С. Ю. Ившин // Научно-технические ведомости Санкт-Петербургского государственного политехнического университета. Экономические науки. - 2014. - № 1 (187). - С. 35-41.

12. Казарина Л. А. Мотивация персонала в условиях экстернализации логистических функций / Л. А. Казарина // Логистика сегодня. - 2007. — № 3. - 164-171.

13. Фоменко Е. В. Аутсорсинг как перспективная форма взаимодействия компаний / Е. В. Фоменко // Экономика. Право. Печать. Вестник КСЭИ - 2013. — № 3. - С. 371-378.

14. Кузнецова А. С. Этапы перехода предприятия на аутсорсинг / А. С. Кузнецова // Наука и современность. - 2011. - № 9-2. - С. 188-192.

\section{References}

1. Beketov N. V. Management problems of economic stability and competitiveness of enterprises. Natsional'nye interesy: prioritety $i$ bezopasnost' = National interests: priorities and security, 2008, no. 4 (25, pp. 23-27. (In Russian).

2. Davydkin E. V. Outsourcing as a function of effective business process management. Aktual'nye voprosy ekonomicheskikh nauk = Topical issues of economic sciences, 2011, no. 22-2, pp. 139-144. (In Russian).

3. Womack James P., Jones Daniel T. From Lean Production to the Lean Enterprise. Harvard Business Review on Managing the Value Chain. Garvard Business School Publishing, 2000, pp. 221-251. (Russ. ed. Womack James P., Jones Daniel T. Ot berezhlivogo proizvodstva $\mathrm{k}$ berezhlivomu predpriyatiyu. Postroenie tsepochki sozdaniya stoimosti. Moscow, Yunaited Press Publ., 2007, pp. 221-251.).

4. Heywood J. Brian The Outsourcing Dilemma. The search for competitiveness. New York, Pearson Education Limited, 2001. 207 p. (Heywood J. Brian Autsorsing: v poiskakh konkurentnykh preimushchestv. Moscow, Vil'yams Publ., 2002. 176 p.).

5. Dikikh Yu. V. Outsourcing in process of creating the finished products. Aktual'nye problemy gumanitarnykh i estestvennykh nauk = Topical problems in Humanities and Natural Sciences, 2013, no. 12-1, pp. 264-267. (In Russian).

6. Kolodin V. S. Logistics systems in industrial and commercial activities. Izvestiya Irkutskoi gosudarstvennoi ekonomicheskoi akademii = Izvestiya of Irkutsk State Economics Academy, 2011, no. 6, pp. 99-103. (In Russian).

7. Kazarina L. A. Logisticheskie uslugi [Logistic Services]. Irkutsk, Baikal State University of Economics and Law Publ., 2006. 158 p.

8. Kuznetsova A. S. Outsourcing as an instrument of survival in modern economy. Aktual'nye voprosy ekonomicheskikh nauk = Topical issues of economic science, 2011, no. 18, pp. 60-65. (In Russian).

9. Bugakov V. M., Bychkov V. P., Bychkov D. V. , Shibaev M. A. Outsourcing of business processes as an important factor in rational organization of transport services (on materials of furniture enterprises of regional economy). Region: sistemy, ekonomika, upravlenie = Region: Systems, Economics, Management, 2014, no. 1 (24), pp. 79-86. (In Russian).

\section{Baikal Research Journal}


10. Kalashnikov A. N. Outsourcing as a form of effective use of human capital. Belgorodskii ekonomicheskii vestnik = Belgorod Economic Bulletin, 2011, no. 1-2 (61-62), pp. 42-46. (In Russian).

11. Ivshin S. Iu. A comprehensive analysis of the concept of «logistics outsourcing». Nauchno-tekhnicheskie vedomosti Sankt-Peterburgskogo gosudar-stvennogo politekhnicheskogo universiteta. Ekonomicheskie nauki $=$ St. Petersburg State Polytechnical University Journal. Economics, 2014, no. 1 (187), pp. 35-41. (In Russian).

12. Kazarina L. A. Staff motivation in terms of externalization of logistics functions. Logistika segodnya = Logistics Today, 2007, no. 3, pp. 164-171. (In Russian).

13. Fomenko E. V. Outsourcing as a promising form of companies' interaction. Ekonomika. Pravo. Pechat'. Vestnik KSEI = Economy. Law. Printing. Bulleting of KSEI, 2013, no. 3, pp. 371-378. (In Russian).

14. Kuznetsova A. S. Stages of enterprise transition to outsourcing. Nauka i sovremennost' = Science and Modernity, 2011, no. 9-2, pp. 188-192. (In Russian).

\section{Информация об авторе}

Казарина Лариса Анатольевна - кандидат экономических наук, доцент, кафедра менеджмента, маркетинга и сервиса, Байкальский государственный университет, 664003, г. Иркутск, ул. Ленина, 11, e-mail: kazalar@yandex.ru.

\section{Author}

Larisa A. Kazarina - PhD in Economics, Associate Professor, Chair of Management, Marketing and Service, Baikal State University, 11 Lenin St., 664003, Irkutsk, e-mail: kazalar@yandex.ru.

\section{Для цитирования}

Казарина Л. А. Аутсорсинг функций как инструмент повышения конкурентоспособности фирмы / Л. А. Казарина // Baikal Research Journal. — 2018. — T. 9, № 1. — DOI : 10.17150/2411-6262.2018.9(1).9.

\section{For Citation}

Kazarina L. A. Outsourcing of Functions as a Tool of Increasing Company's Competitiveness. Baikal Research Journal, 2018, vol. 9, no. 1. DOI: 10.17150/2411-6262.2018.9(1).9. (In Russian).

\section{Baikal Research Journal}

